\title{
Ege Üniversitesi Hastanesi veri tabanında kayıtlı larinks kanserli olguların epidemiyolojik ve genel sağkalım özellikleri
}

Epidemiological and survival profile of laryngeal cancer patients recorded in the database of Ege University Medical School

\begin{tabular}{|c|c|c|c|}
\hline Göksel Turhal ${ }^{1}$ (iD & Fetih Furkan Şahin ${ }^{1}$ (iD & Kerem Öztürk ${ }^{1}$ (D) & Özlem Akagündü $z^{2}$ (D) \\
\hline Serdar Akyıldız' (iD) & Mustafa Esassolak ${ }^{2}$ (iD & Ümit Uluöz' & Ali Veral ${ }^{3}$ (D) \\
\hline Ulus Ali Şanlı ${ }^{4} \mathbb{D}$ & \multicolumn{3}{|l|}{ Ayşe Caner ${ }^{5}$ iD } \\
\hline \multicolumn{4}{|c|}{$\begin{array}{l}{ }^{1} \text { Ege Üniversitesi Tıp Fakültesi Kulak Burun Boğaz Hastalıkları Anabilim Dalı, İzmir, Türkiye } \\
{ }^{2} \text { Ege Üniversitesi Tıp Fakültesi Radyasyon Onkolojisi Anabilim Dalı, İzmir, Türkiye } \\
{ }^{3} \text { Ege Üniversitesi Tıp Fakültesi Patoloji Anabilim Dalı, İzmir, Türkiye } \\
{ }^{4} \text { Ege Üniversitesi Tıp Fakültesi Tıbbi Onkoloji Bilim Dalı, İzmir, Türkiye } \\
{ }^{5} \text { Ege Üniversitesi Tıp Fakültesi Kanserle Savaş Uygulama ve Araştırma Merkezi, İzmir, Türkiye }\end{array}$} \\
\hline
\end{tabular}

\section{Özet}

Amaç: Bu çalışmada Ege Üniversitesi Kanserle Savaş Uygulama ve Araştırma Merkezi (EÜKAM) sisteminde kayıtı olan larinks kanseri tanısı alan hastaların demografik özellikleri ile birlikte malignite kliniğine göre genel sağkalımlarının araştırılması amaçlanmıştır.

Gereç ve Yöntem: EÜKAM'da görevli kanser kayıt teknik ekibi tarafından kaydedilen 1992-2016 yılları arasında Ege Üniversitesi'nde tanı, tedavi ve takip sürecinde yer alan 3144 olgunun yaşı,cinsiyeti, histopatolojisi, tümör evresi, uygulanan tedavi şekli, takip süresi ve sağkalım durumu retrospektif olarak analiz edilmiştir.

Bulgular: 3144 olgunun ortalama yaşı $59.4 \pm 10.5$ saptanmıştır. En sık histopatolojik tip \%97.4 ile karsinom olarak, en sık gözlenen evre durumu \%47.1 ile lokal sınırı evre olarak saptanmıştır. Tüm olgu serisinin 5, 10, 15 ve 20 yıllık genel sağkalımları ise sırasıyla \%67, \%48.6, \%33.8 ve \%23.5 olarak bulunmuştur.

Sonuç: Larinks kanserleri genel sağkalımında tümör evresi, yaş gibi faktörlerin anlamlı olarak etkili olduğu saptanırken cinsiyetin sağkalım üzerinde anlamlı etkisinin olmadığı görülmüştür. Ayrıca son yıllarda organ koruyucu tedavi modellerindeki alternatif seçenek ve başarı oranlarında artış olduğu, bunun yanında larinks kanseri insidansında artışın günümüze kadar devam ettiği saptanmıştır.

Anahtar Sözcükler: Larinks kanseri, epidemiyoloji, sağkalım.

\section{Abstract}

Aim: The scope of this study was to investigate the demographic characteristics of laryngeal cancer and the factors that may effect the overall survival of laryngeal cancer in patients recorded in Ege University Cancer and Research Center (EUKAM) database.

Materials and Methods: Data of 3144 laryngeal cancer patients registered at EUKAM between 19922016; diagnosis, age, gender, histopathology, tumor stage, treatment modalities, follow-up period and latest status were retrospectively evaluated.

\footnotetext{
Sorumlu yazar: Fetih Furkan Şahin

Ege Üniversitesi Tıp Fakültesi Kulak Burun Boğaz Hastalıkları

Ana Bilim Dalı, İzmir, Türkiye

E-posta: fetihfurkansahin@gmail.com
} 
Results: The average age of 3144 patients was $59.4 \pm 10.5$ years. $94.9 \%$ of the cases were male and $5.1 \%$ were female. The most common histopathological type was carcinoma with the percentage of $97.4 \%$, and the most common stage was locally limited with the percentage of $47.1 \%$. The 5, 10,15 and 20 -year overall survival rates were $67 \%, 48.6 \%, 33.8 \%$ and $23.5 \%$, respectively.

Conclusion: Tumor stage and age were found to be significantly effective on survival of laryngeal cancers, on the other hand gender did not have a significant effect on survival. In last decades there has been an increase in alternative options and success rates in larynx preservation treatment modalities in recent years, as well as an increase in the incidence of laryngeal cancer.

Keywords: Laryngeal cancer, epidemiology, survival.

\section{Giriş}

2018 yılı global kanser istatistiklerine göre larinks kanseri, tüm dünyada yeni gelişen kanserlerin \%1'ini oluşturmakta olup23. en sık görülen kanserdir. Tüm kanserler içerisinde kansere bağlı ölümlerin de \%1'ini oluşturmaktadır (1). Amerikan ulusal kanser enstitüsü verilerine göre larinks kanserlerinin toplam 5 yıllık sağkalım oranı $\% 60.3$ olarak bildirilmiştir (2). Larinks kanserlerinin \%54'ü tanı anında erken evrede saptanmakta olup erken evre larinks kanserinin 5 yıllık sağkalımı $\% 77.4 \quad$ olarak raporlanmıştır.Larinks kanseri en sık glottik bölgede görülmektedir ve erken glottik bölge larinks kanserinde 5 yıllık sağkalım \%83'e çıkabilmektedir (3). Bu oranları ile larinks kanseri, solunum yolunun sağkalımı en yüksek kanserlerindendir. Larinks kanserlerine sıklıkla 6. ve 7 . dekatlarda rastlanmakta olup olguların \%1'i 30 yaşın altındadır.

Larinks kanserinin bilinen en önemli nedenleri aşırı tütün ve alkol kullanımıdır. Larinks kanseri etyolojisinde genetik faktörlerin yanı sıra metal ve plastik sanayi ürünlerine maruziyet, kronik olarak odun tozuna, polisiklik aromatik bileşiklere, verniğe maruziyet ile asbestoz da larinks kanseri için risk faktörleri olarak bildirilmektedir $(4,5)$. Ayrıca tiroid gland maligniteleri, tüberkülöz lenfadenit gibi nedenlerle boyun bölgesine verilen radyoterapi (RT) sonrasında bildirilen laringeal skuamöz hücreli karsinom olguları mevcuttur (6). Laringofaringeal reflünün tek başına veya alkol, tütün kullanımı ile birlikte sinerjik olarak larinks kanserine neden olabileceği de bildirilmiştir (7).

Larinks kanserlerinde en sık gözlenen semptom ses kısıklığıdır. Özellikle glottik bölge larinks karsinomlar ses kısıklığı ile erken bulgu vermesi ve lenfovasküler drenajının da sınırlı olması nedeniyle erken tanı almaktadır (8). Supraglottik bölge yerleşimli larinks kanserlerinde otalji, disfaji, boyun kitlesi semptomları ön plana çıkar, disfoni gelişmesi supraglotik tümörün transglottik bir kitleye dönüştüğünü gösterebilir. Subglottik alanda gelişen larinks kanserleri ise sıklıkla hava yolu obstrüksiyonu ile bulgu verirler. Supraglottik ve subglottik bölge kanserlerinde lenfovasküler yollar ile bölgesel lenf nodu veya uzak metastaz oranları artmaktadır. Larinks malign neoplazmlarında en sık gözlenen histopatolojik tip skuamöz hücreli kanserdir. Nadiren verrüköz karsinomlar, adenokarsinomlar, nöroendokrin tümörler ve sarkomlar saptanabilmektedir. Tanı anındaki kanser evresi sosyodemografik faktörler, histopatolojik tip, hastaya ya da hekime bağlı gecikmeler ile ilişkilidir. Düşük sosyoekonomik düzey, yoğun tütün ve alkol kullanımı, bekar, yaşlı ve erkek hastalarda kanserin daha ileri evrelerde tanı aldığı saptanmıştır (9). Tümörün yerleşim yeri, histopatolojik tanısı, yayılımı, boyutuna göre tedavi modelleri cerrahi, RT, radyokemoterapi şeklinde değişiklik göstermektedir.

Özellikle Ege Bölgesi olmakla birlikte tüm Türkiye'den larinks kanseri tanılı hastaların tedavi ve takibi konusunda deneyimli olan Ege Üniversitesi Tıp Fakültesi ve bünyesinde yer alan E.Ü Kanserler Savaş Uygulama ve Araştırma Merkezi (EÜKAM), olgulara ait detaylı bilgileri içeren geniş bir veritabanına sahiptir. $\mathrm{Bu}$ çalışmada, EÜKAM'da kayıtlı olan larinks malign neoplazmı tanılı tüm olguların genel demografik özellikleri, tümör evresi, tedavi şekilleri, sağkalım özellikleri araştırılmıştır.

\section{Gereç ve Yöntem}

Bu çalışmada, EÜKAM veri tabanında kayıtı olan 1992-2016 yılları arasında larinks kanseri tanısı alan olgular C32 (Larinks Malign Neoplazmı) tanı kodu ile taranmıştır.Tarama sonucunda toplam 3144 olgu çalışmaya dahil edilmiştir. Olguların yaş, cinsiyet gibi demografik özellikleri, TNM evreleri, uygulanan tedavi şekilleri, takip süreleri, sağkalım özellikleri retrospektif olarak incelenmiştir. Çalışma için gerekli etik kurul onayı alınmıştır. 
Elde edilen veriler, SPSS 22.0 versiyonu (SPSS Inc, Chicago, Illinois, USA) ile analiz edilmiştir. Ki-kare testi kategorik verilerin karşılaştırmasında kullanışmıştır. Non-parametrik değişkenlerin analizinde Mann-Whitney $U$ testi kullanılmıştır. Elde edilen sonuçlar uygun olduğu yerde ortalama, yüzde (\%), minimum-maksimum, median olarak ifade edilmiştir. Genel sağkalım analizi için Kaplan-Meier yöntemi ile yapılmış olupfarklı değişkenlere göre sağkalım karşılaştırmaları için Log Rank (Mantel-Cox), Breslow (Generalized Wilcoxon) ve Tarone-Ware istatistikleri kullanılmıştır. $\quad p<0.05$ değeri istatistiksel olarak anlamlı kabul edilmiştir.

\section{Bulgular}

Toplam 3144 olgunun ortalama yaşı $59.4 \pm 10.5$ yıl(aralık 24-96 yıl)olarak saptandı. 2984 (\%94.9) olgu erkek, 160 (\%5.1) olgu kadındı.92 olgu (\%2.9) 40 yaşın altında, 3052 olgu (\%97.1) 40 yaş ve üstü saptandı. Histopatolojik dağılıma bakıldığında \%97.4 olguda karsinom, \%1.9 olguda lenfoma, \%0.4 olguda melanom, \%0.2 olguda ise sarkom saptandı. $\mathrm{Bu}$ çalışmada tümörlerin TNM evrelemesi in situ, lokal sınırlı, lokal ileri, lokal bölgesel ve metastatik hastalık olarak gruplandırıldı. Kayıtlı verilerine ulaşılan 3144 olgudan 1404'ünün TNM evrelemesinin dağılımı incelendiğinde \%9.3 in situ, \%47.1 lokal sınırlı, \%12.7 lokal ileri, \%25.4 lokal bölgesel,
\%5.6 metastatik hastalık izlendi. 3144 olgunun 351 'inin (\%11.2) hastalara ait bazı faktörler ile tedavi almamış olduğu görüldü. Buna karşılık 1316 (\%41.9) olgu primer cerrahi, 834 (\%26.5) olgu cerrahi ve ardından postoperatif adjuvan RT, 643 (\%20.5) olgu primer küratif RT veya kemoradyoterapitedavisi aldı. Olgu serisine ait demografik ve klinik özelliklerine göre dağılım (Tablo-1)'de gösterildi.

Tüm olguların genel $5,10,15$ ve 20 yıllık sağkalım oranları sırasıyla \%67, \%48.6 , \%33.8 ve \%23.5 olarak bulundu. Olguların evrelemeye analiz edildiğinde, 5 yıllık genel sağkalım in situ hastalıkta \%83.1, lokal sınırlı evrede \%80.9, lokal ileri evrede \%64.4, lokal bölgesel evrede \%52.6 , uzak metastatik hastalıkta \%27.6 olarak saptandı (Şekil-1). Artan evrenin, sağkalımın azalmasında istatistiksel olarak anlamlı şekilde etkili olduğu gözlendi $(p<0.001)$. Erkeklerde ve kadınlarda 5 yıllık genel sağkalım sırasıyla \%66.4 ve \%68.4 olarak bulundu. Cinsiyetin sağkalım üzerinde istatistiksel olarak anlamlı etkisinin olmadığı görüldü ( $p>0.05)$. 40 yaş altı olgular 5 yıllık genel sağkalım \%82.1 olarak saptanırken, 40 yaş ve üstü olgularda 5 yıllık genel sağkalım $\% 66.5$ olarak bulundu. 40 yaş altı ve üstü olguların genel sağkalım oranları arasında istatistiksel olarak anlamlı farklılık saptandı $(p<0.001)$. Olgu serisinin sağkalım analizleri (Tablo-2)'de gösterildi.

Tablo-1. Larinks kanseri olgu serisinin demografik ve klinik özelliklerine göre dağılımı.

\begin{tabular}{llcc}
\hline & & Sayı & Yüzde \\
\hline Cinsiyet & Erkek & 2986 & 94,8 \\
Histopatoloji & Kadın & 163 & 5,2 \\
& Karsinoma & 3068 & 97,5 \\
& Lenfoma & 60 & 1,9 \\
& Melanoma & 14 & 0,4 \\
Evreleme & Sarkoma & 7 & 0,2 \\
& In situ & 131 & 9,3 \\
& Lokal Sınırlı & 662 & 47,1 \\
& Lokal Ileri & 178 & 12,7 \\
Tedavi & Lokal Rejyonel & 356 & 25,4 \\
& Uzak Metastatik & 77 & 5,6 \\
& Yalnızca Cerrahi & 1316 & 41,9 \\
& Cerrahi ve RT/KRT & 834 & 26,5 \\
& RT/KRT & 643 & 20,5 \\
\hline
\end{tabular}

(RT: Radyoterapi , KRT: Kemoradyoterapi) 
Tablo-2. Olgu serisinin farklı değişkenlere göre genel sağkalım analizleri.

\begin{tabular}{|c|c|c|c|c|c|}
\hline & & 5 yıllık & 10 yıllık & 15 yıllık & 20 yıllık \\
\hline \multicolumn{2}{|c|}{ Tüm Olgular } & $\% 67$ & $\% 48,6$ & $\% 33,8$ & $\% 23,5$ \\
\hline \multirow{5}{*}{ Evre } & İn situ & $\% 83,1$ & $\% 65,7$ & & \\
\hline & Lokal sınırlı & $\% 80,9$ & $\% 61,8$ & $\% 42,4$ & \\
\hline & Lokal ileri & $\% 64,4$ & $\% 39,6$ & $\% 30,3$ & \\
\hline & Lokal rejyonel & $\% 52,6$ & $\% 30,7$ & $\% 21,9$ & \\
\hline & $\begin{array}{l}\text { Uzak } \\
\text { metastatik }\end{array}$ & $\% 27,6$ & $\% 6,9$ & & \\
\hline \multirow{2}{*}{ Cinsiyet } & Erkek & $\% 66,4$ & $\% 48,4$ & & \\
\hline & Kadın & $\% 68,4$ & $\% 51,3$ & & \\
\hline \multirow{2}{*}{ Yaş } & 40 yaş altı & $\% 82,1$ & $\% 73,9$ & $\% 64,1$ & $\% 50,5$ \\
\hline & 40 yaş ve üstü & $\% 66,5$ & $\% 47,8$ & & \\
\hline
\end{tabular}

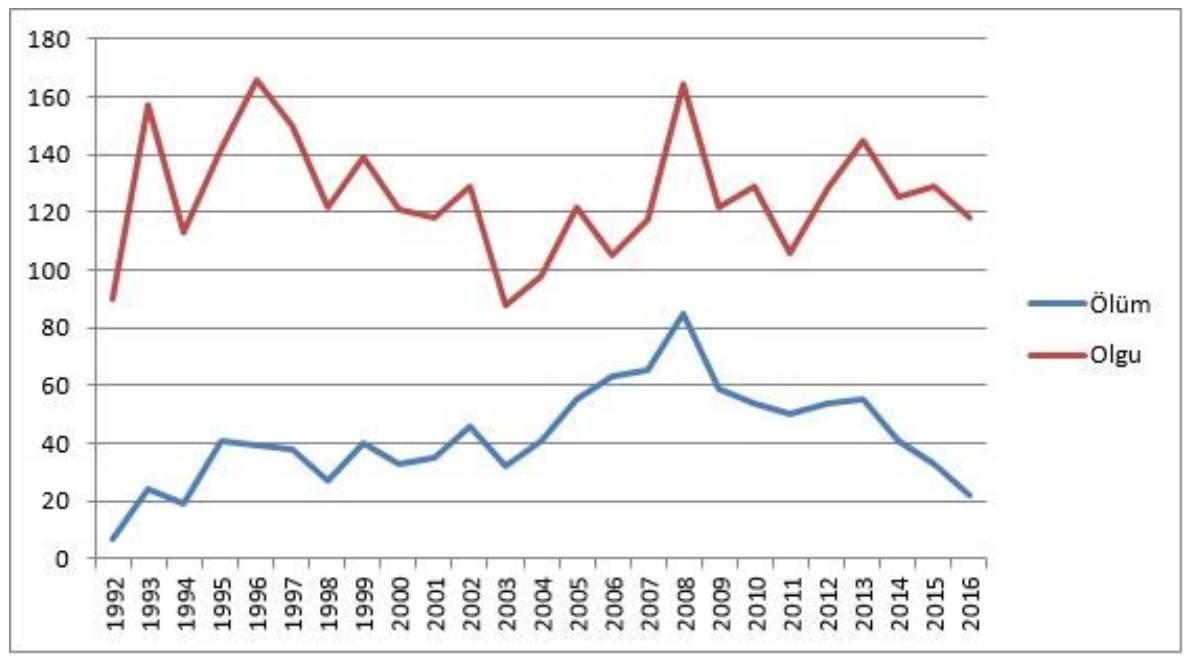

Şekil-1. Evrelemeye göre genel sağkalım analizi.

\section{Tartışma}

Bu çalışmada EÜKAM veri tabanında 1992-2016 yılları arasında kayıtları tutulan 3144 larinks kanseri hastasının retrospektif analizi yapıımış, elde edilen bulgular global epidemiyolojik veriler ile karşılaştırılmıştır. Cilt kanserleri hariç tutulduğunda baş boyun bölgesinde skuamöz hücreli karsinomun en fazla görüldüğü yer larinkstir. ASCO (American Society of Clinical Oncology) 2019 yılı verilerine göre yeni tanı alan oral kavite ve orofarinks kanserlerinin üçte biri oranında yani tanı larinks malign neoplazmı bildirilmiştir. Oysaki ülkemizde ve bölgemizdeki diğer ülkelerde beklenen yeni tanı larinks kanserlerinin oranı diğer baş boyun bölgesi kanserlerinden halen daha yüksektir (10). Türkiye Cumhuriyeti Sağlık Bakanlığı'ıın 2011-2015 yılları arasındaki kanser istatistik verilerine göre bu yıllar arasında yeni tanı alan 13.778 baş boyun bölgesi kanseri vakalarının \%46'sının larinks kanser tanısı aldığı saptanmıştır (11).Tüm baş boyun bölgesi için erkeklerde insidans ve standartize edilmiş hız kadınlara göre daha yüksektir. Bu çalışmada erkek:kadın oranı 18.6 olarak bulunmuştur, güncel literatürde ise dünya genelinde erkek:kadın oranının yaklaşık 5 olarak 
bulunduğu bildirilmektedir. Yapılan epidemiyolojik çalışmalarda diğer baş boyun kanserleri gibi larinks kanserlerinin de yaş ile birlikte insidansının arttığı bilinmektedir. 40 yaşında üzerinde larinks kanserlerinin dünya genelinde görülme insidansı \%95 üzerinde iken bu çalışmada olguların \%97.1'i 40 yaş ve üzeri saptanmıştır.

Baş boyun kanserlerinde hemen tüm bölgelerde en sık görülen histopatolojik alt grup karsinomlardır. Çalışmamızda larinks kanserlerinde beklendiği gibi en sık histopatolojik alt grup \%97.4 ile karsinom olarak saptanmıştır. Karsinom alt grupta çok büyük oranda skuamöz hücreli karsinom görülmekle birlikte daha nadiren verrüköz karsinom, adenokarsinom ve küçük hücreli karsinom görülebilmektedir. Larinksin primer lenfoma, sarkoma ve melanomaları çok nadir gözlenmekte olup literatürde \%1'in altında bildirilmişlerdir $(12,13)$. Bu çalışmada da benzer şekilde lenfoma, melanoma ve sarkoma sırasıyla $\% 1.9$, \%0.4 ve \%0.2 oranlarında gözlenmiştir.

Son yıllarda larinks kanserine yönelik hem cerrahi hem de cerrahi olmayan tedavi modelleri belirgin gelişim göstermiştir. Organ koruyucu cerrahi yaklaşımlar, gelişen definitifRT yaklaşımları, örneğin IMRT (intensity-modulated radiotherapy) başarı oranları ile popülerleşen tedavi modelleridir.Lokal ileri rezektabl laringeal kanserlerde veya uzak metastatik hastalıkta CCRT (concurrent chemoradiotherapy-eş zamanlı kemoradyoterapi), ICT (indüksiyon kemoterapi),

bioradyoterapi (BRT/setuksimab+RT) gibi organ koruyucu kombine tedavi modellerinin uzun yıllardır yüksek genel sağkalım oranları ile başarı ile uygulanmakta olduğu bildirilmektedir (14). Öte yandan ICRT (indüksiyon kemoradyoterapi) ve adjuvan RT ile elde edilen hastalıksız sağkalım sürelerinin CCRT ile karşılaştırıldığında belirgin yüksek olduğu da bildirilmektedir (15). Ancak günümüze kadar larinks kanserlerinde lokal kontrol açısından konservatif cerrahi ve kombinekemoradyoterapi veya hedefe yönelik tedavi modellerini kaşılaştıran randomize kontrollü çalışma az sayıda mevcuttur (16). Toplam 332 hastada yürütülen indüksiyon kemoterapi ve RT ile cerrahi ve RT tedavi modellerinin karşılaştııılığı randomize kontrollü VA (Veterans Affairs Laryngeal Cancer Study Group)çalışmasında iki tedavi modelinin sağkalım üzerinde benzer sonuçlarının olduğu, dolayısı ile organ koruyucu tedavi olarak indüksiyon kemoterapi ve RT'nin en az larenjektomi kadar etkili olduğu raporlanmıştır (17). Güncel bir kohort çalışmada ise cerrahisiz sağkalım üzerine indüksiyon kemoterapi ve RT ile eş zamanlı kemoradyoterapinin benzer düzeyde etkili olduğu görülmekle birlikte eş zamanlı kemoradyoterapinin indüksiyon kemoterapi veya yalnızca RT ile karşılaştırıldığında, lokorejyonel kontrol ve larinks prezervasyonu açılarından belirgin olarak daha etkili olduğu bildirilmiştir (18).

Gelişen tedavi modellerine rağmen tüm baş boyun kanserlerinin toplam sağkalımı geçmiş yıllarda olduğu gibi ortalama \%50 civarında seyretmektedir (19). SEER(Surveillance, Epidemiology, and End Results) veri tabanında 1973-2013 yılları arasındaki verilere göre larinks kanserinin 5 yıllık toplam sağkalım oranları $\% 47$ 'lerde olarak bildirilmiştir (20). Avrupa ülkelerinde yürütülen popülasyon bazlı EUROCARE-5 çalışmasında larinks kanserlerinde 5 yıllık rölatif sağkalım \%62 olarak bildirilmiştir (21). Larinks kanserlerinde hastalığa spesifik ve genel sağkalım yaş, cinsiyet, etnisite, histopatoloji, etyoloji, hastalık evresi gibi çok sayıda faktörden etkilenebilir. Li ve arkadaşlarının yaptığı bir kohort çalışmasında glottik ve supraglottik kanserlerin genel sağkalımının erkeklerde kadınlara göre istatistiksel olarak belirgin daha düşük olduğu (sırasıyla $\% 79,7$ vs. $\% \% 83,2$ ve $\% 54,6$ vs $\% 60,4)$ buna karşıllık subglottik larinks kanserinde genel sağkalımın benzer oranda olduğu $(\% 53,3$ vs $\% 59,8)$ görülmüştür (22). Çalışmamızda larinks kanserlerinin 5 yıllık sağkalım oranı EUROCARE5 çalışması ile benzer olmakla birlikte, 10 yıllık sağkalım oranları, SEER 5 yıllık sağkalım oranı ile benzerlik göstermektedir.Cinsiyetin genel sağkalımı etkileyen bir faktör olduğunu ve kadınlarda sağkalımın daha yüksek saptandığını bildiren güncel kohort çalışmaları da mevcuttur (15). Ancak çalışmamızda cinsiyetin genel sağkalım üzerinde istatistiksel olarak belirgin bir etkisinin olmadığı sonucuna varılmıştır.

Gelişmiş ülkelerde erken evre larinks karsinomlarında RT ön plandayken ülkemizde ve merkezimizde cerrahi tedavi modelleri ön planda olmaya devam etmektedir. Sağlık Bakanlığı'na ait veriler ile benzer şekilde olgu serimize ait 5 yıllık genel sağkalım oranı \%67'dir. 1992 yılından 2016 yılına kadar takibi yapılan larinks kanseri serimizde yıllar içerisinde insidansın artmış olduğu görülmekle birlikte son yıllarda sigara 
tüketimindeki azalmaya da bağlı olarak insidans oranı artışında azalma bildirilmektedir. Gelişmiş ülkelerde bölgesel farklılıklar olmakla birlikte larinks kanseri insidansı tüm baş boyun bölgesi kanserlerinde üst sıralardadır. Benzer şekilde EÜKAM'da takipli tüm baş boyun kanserleri tarandığında en yüksek insidans oranı \%45,3 ile larinks kanserlerinde görülmektedir (23). Yıllar içerisinde baş boyun kanseri olgu sayısında artış gözlenmektedir ancak başta sigara tüketimine karşı olarak önleyici tıp yaklaşımları ve alınan önlemler ile özellikle larinks karsinomlarında insidans artış hızında düşüş ve hatta insidansta azalma ön görülmektedir.

Çıkar çatışması: Yazarlar çıkar çatışması beyan etmemişlerdir.

\section{Kaynaklar}

1. Bray F, Ferlay J, Soerjomataram I, Siegel RL, Torre LA, Jemal A. Global cancer statistics 2018: GLOBOCAN estimates of incidence and mortality worldwide for 36 cancers in 185 countries. CA Cancer J Clin. 2018;68(6);394-424.

2. Surveillance, Epidemiology and End Result Program. Cancer stat facts: Laryngeal cancer. National Cancer Institute. https://seer.cancer.gov/statfacts/html/laryn.html

3. Survival Rates for Laryngeal and Hypopharyngeal Cancers. American Cancer Society. https://www.cancer.org/cancer/laryngeal-and-hypopharyngeal-cancer/detection-diagnosis-staging/survivalrates.html

4. Koç C. Kulak Burun Boğaz Hastalıkları ve Baş Boyun Cerrahisi. 1. Baskı, Ankara: Güneş Kitabevi Ltd Şti, 2003; 1183-216.

5. Wunsch Filho V. The epidemiology of laryngeal cancer in Brazil. Sao Paulo Med J. 2004 Sep 2;122(5):188-94.

6. Koufman JA, Burke AJ. The etiology and pathogenesis of laryngeal carcinoma. Otolaryngol Clin North Am 1997; 30: 1-19.

7. Dagli S, Dagli U, Kurtaran H, Alkim C, Sahin B. Laryngopharyngeal reflux in laryngeal cancer. Turk J Gastroenterol. 2004 Jun;15(2):77-81.

8. Mendenhall WM, Million RR, Stringer SP, Cassisi NJ. Squamous cell carcinoma of the glottic larynx: a review emphasizing the University of Florida philosophy. Review. South Med J. 1999 Apr;92(4):385-93.

9. Teppo $\mathrm{H}$, Koivunen P, Hyrynkangas K, Alho OP. Diagnostic delays in laryngeal carcinoma: Professional diagnostic delay is a strong independent predictor of survival. Head Neck 2003; 25: 389-94.

10. Larizadeh M H, Damghani M A, M. Epidemiological Characteristics of Head and Neck Cancers in Southeast of Iran. Iran J CancerPrev. 2014;7(2):80-6.

11. Kara F, İlter H, Keskinkılıç B ve ark. Türkiye Kanser İstatistikleri 2015. Halk Sağlığı Genel Müd. Sağlık Bakanlığı 2018.

12. Kim KH, Kim RB, Woo SH. Individual participant data meta-analysis of primary laryngeal lymphoma: focusing on the clinical characteristics and prognosis. Laryngoscope 2015;125:2741-8.

13. Karatayli-Ozgursoy S, et al. Non-epithelial tumors of the larynx: a single institution review. Am J Otolaryngol. 2016;37(3):279-85.

14. Hideya Y, Gen S, Satoaki Net al. Radiotherapy for locally advanced resectable T3-T4 laryngeal cancerdoes laryngeal preservation strategy compromise survival? J Radiat Res. 2018;59(1):77-90.

15. Stokes WA, Jones BL, Bhatia $S$ et al. A comparison of overall survival for patients with T4 larynx cancer treated with surgical versus organ-preservation approaches: A National Cancer Data Base analysis. Cancer. 2017;123(4):600-8.

16. Sert F, Kaya I, Ozturk K, Esassolak M. Patterns of failure for early-stage glottic carcinoma: 10 years' experience in conformal radiotherapy era. J Can Res Ther 2019;15:576-81.

17. Department of Veterans Affairs Laryngeal Cancer Study Group. Induction chemotherapy plus radiation compared with surgery plus radiation in patients with advanced laryngeal cancer. N Engl J Med 1991; 324:1685-90.

18. Forastiere AA, Zhang Q, Weber RS, et al. Long-term results of RTOG 91-11: a comparison of three nonsurgical treatment strategies to preserve the larynx in patients with locally advanced larynx cancer. $\mathrm{J}$ Clin Oncol. 2013;31(7):845-52. doi:10.1200/JCO.2012.43.6097. 
19. Boring CC, Squires TS, Tong T, Montgomery S. Cancer statistics, 1994. CA Cancer J Clin. 1994;44(1):7-26.

20. Bean MB, Liu Y, Jiang R, et al. Small Cell and Squamous Cell Carcinomas of the Head and Neck: Comparing Incidence and Survival Trends Based on Surveillance, Epidemiology, and End Results (SEER) Data. Oncologist. 2019;24(12).

21. Gattaa G, Bottaa L, Sánchez M J ve ark. Prognoses and improvement for head and neck cancers diagnosed in Europe in early 2000s: The EUROCARE-5 population-based study. Eur J Cancer. 2015;51(15):2130-43.

22. Li H, Li EY, Kejner AE. Treatment modality and outcomes in larynx cancer patients: A sex based evaluation. Head Neck. 2019;41(11):3764-74.

23. Akagündüz ÖÖ, Cosgun G, Esassolak $M$ ve ark. Ege Üniversitesi Tıp Fakültesi veri tabanında kayıtlı başboyun kanserli olguların epidemiyolojik ve genel sağ kalım özellikleri. Ege Tıp Dergisi. 2019;58:114-9. 